\title{
Effect of Core Competence and Brand Personality of Short Video Websites on User Loyalty
}

\author{
Wei CUI, Kai LIAO, Zi-yang LIU
}

\begin{abstract}
Influenced by the strong demand for fragmented entertainment from network users, the short video industry has entered an unprecedented period of rapid development, but any emerging industry goes through a life cycle. The purpose of this article is to explore the impact of core competitiveness and brand personality on user loyalty in short video industry by using questionnaire survey for Chinese short video users and statistical analysis based on survey data, so as to provide suggestions for short video websites to improve user loyalty and prolong life cycle. Core competitiveness and brand personality are considered as independent variables, user perceived value characteristics as the moderator variable, and user loyalty as the dependent variable to construct the research model. The SPSS and AMOS statistical analysis tools are applied to reliability analysis, validity analysis, and structural equation model analysis of the survey data. The Results show that the core competitiveness of the short video industry has no positive effect on user perceived value; and the brand personality has a significant positive impact on the user perceived value; the core competitiveness of the short video industry has a significant positive impact on the user loyalty; the brand personality has a significant positive impact on the user loyalty; and the user perceived value has a significant positive impact on the user loyalty. Based on the above results, we suggest the short video website improve its core competitiveness through creating original videos, and adopting diversified content production modes, using network transmission and mass media to promote short video products, so as to strengthen the brand communication, shape the brand image and enhance the user perceived value, etc.
\end{abstract}

Keywords: brand personality; core competitiveness; short video website; user loyalty; user perceived value

\section{INTRODUCTION}

Short videos emerged in the United States in April 2011, when the technology platform Viddy released a social application that enabled registered users to release 30 -second videos. These videos could be edited to include audio effects. On this platform, video production is simple and the market threshold is low. Thereafter, Viddy was integrated with social media platforms such as YouTube, Facebook, and Twitter, thereby opening the new door for the short video socialization. By 2017, Musical.ly, a wellknown short video software of music in North America, has more than 2 million daily active users worldwide, including over 6 million active users in North America. (Dotc United Group, U. S., Chapter of 2018 H1 Global App Market Report.)

In China, Tencent proposed the concept of "panentertainment" in 2011. The pan-entertainment industry has gradually become an important pillar of China's digital economic development. Short videos, as a new media to provide refined and directional products after the era of live broadcasting, has a rapid development. In a real sense, the first year of the short video was 2017. Influenced by the high demand for fragmented entertainment of network users, especially mobile network users, the industry has ushered in an unprecedented high-speed development period. According to the "2018 China Network audiovisual Development Research Report" released by China Internet audio-visual program service association, as of June 2018, the number of online short video users was 594 million, accounting for $97.5 \%$ of the network video users. It is estimated that the market size of the whole industry will exceed 11 billion 800 million yuan, an increase of 106\% over the same period last year, and the short video users' scale and usage duration show explosive growth trend. Tencent's Weishi, Meitu Xiuxiu's Meipai, Xiaokaxiu, Miaopai, Beijing Microcast Vision Technology's Tik Tok and Huoshan are all subtly changing the way people share information about their lives. Since 2017, major Internet companies have begun to expand their investment in the short video industry. For example, Toutiao announced that it would invest no less than 1 billion yuan to support short video creation. Tencent's "Grain in Ear Plan 2.0" also announced that it would provide 1.2 billion yuan of financial support for content creators, including makers of short videos. Furthermore, Tencent participated in a new round of investment in short video platform-Kuaishou and announced a \$2 billion cash infusion to build the "Big Fish Project", in which Tudou would undertake a short video business. With these developments, the short video industry chain will become increasingly complete, the division of labor is clearer, and the operating efficiency will be improved continuously.

However, any emerging industry will go through a life cycle of development, growth, maturity, and recession. For example, due to lack of ingenuity in technology, on October 28, 2016, Twitter announced that it would shut down Vine, which was its video-sharing mobile application and cut $9 \%$ of its workforce in the world in order to reduce costs. To ensure the viability of an emerging industry so that it will have a long life cycle, its "core competitiveness" must be developed. For the short video industry, if the core competitiveness is its explicit hard core, the brand personality is its soft core. If the short video industry wants to survive in the long run, it must fully understand its core competitiveness, take full advantage of its core competitiveness, take the users as the center, create user loyalty based on value, and create a brand personality for the industry.

The short video industry has existed in China for just a few years. Thus, the core competitiveness and brand personality of this industry should be studied further. This study aims to establish a feasible and exploratory research model and take advantage of the data from China to examine whether the core competitiveness and the composition of brand personality factors of the online short video websites have a high or low impact on user loyalty. This investigation can help provide countermeasures and suggestions on how to achieve the lasting loyalty of users by enhancing the core competitiveness and brand personality of the short video industry. 


\section{LITERATURE REVIEW}

Concerning the definition and measurement of the enterprise's core competitiveness in the context of the Internet, Banerjee [3] defined the core competitiveness as the agglomeration and integration of internal resources; according to the scope and degree of resources used by enterprises, different strategies are formulated. Zhang [32] stated that firms' information technology (IT) application ability formed on the basis of IT resource investment can increase their core competitiveness. Xie [28] proposed that in the context of mobile Internet, enterprises should attach importance to the innovation, user experience, and coordination of resources of core technologies in reconstructing core competitiveness. Qiao and Cao [22] pointed out that in the sharing economy, mining enterprise advantages under network resources is an important element in building the core competitiveness of an enterprise.

In the Internet era, the competition among industries similarly faces the problem in which the product or service experience is highly homogeneous, and the brand image has increasingly become an important means of competition for businesses. However, the image only attracts the consumer's approval, the brand's individuality may lead to loyalty. Concerning the concept and measurement of brand personality in the short video industry, Kelley [33] proposed that "brand personification is conducive to customers' emotional positioning of the brand and easy to obtain customers' psychological identity". Xu [29] conducted an empirical study on social media brand personality from six dimensions: joy, novelty, negativity, care, integrity, and wisdom. Through empirical research, Aaker [1] obtained the dimension scale of brand personality, which is divided into five dimensions: innocence, stimulation, ability, cultivation and roughness.

In terms of definition and measurement of user perceived value, Zeithaml [31] defined user perceived value as the overall measurement of product or service utility by users based on their perception of gain and loss. Lemon [18] believed that value is the basis and link between enterprises and customers; for the strategic purpose of enterprises, delivering customer value is more important than directly defeating competitors. Sun [27] pointed out that customer satisfaction depends on customer perceived service quality and customer expectations. Liu [20] classified the customer value of service enterprises into the following elements: functional, social, emotional, knowledge, and convenience value.

With the advent of China's industry 4.0 era and the formation and development of the Internet environment, many scholars have also introduced the concept of user loyalty into the Internet. Basir [4] stated the ways to realize customer satisfaction and loyalty in ocean transportation service. Frederick [12] explored the online purchase activities of users and revealed that customer loyalty behavior (called e-loyalty) may also occur in the network context. Smith [26] pointed out that the core of user loyalty lies in whether the website operator can properly use IT to establish a good relationship with users. Hu [13] enumerated the following reasons that affect the customer loyalty of Internet enterprises: website design and security, customer value, customer experience, customer satisfaction, customer trust, and personal characteristics of customers. Oliver [21] integrated the two dimensions of loyalty behavior and attitude. Although the change of environment and the marketing strategy of competitors can potentially influence product transformation, consumers are still willing to buy goods or services that they have previously bought, thereby ensuring repeated purchase of the same brand. To measure user loyalty, Shankar [24], Rahul and Tridas [23] described the adoption of behavioral attitudes, while Chaudhuri and Morris [7], Jones and Taylor [14] considered the emotional attitudes.

\section{METHODS}

The research model applied in this study takes the core competitiveness and brand personality of the short video industry as the independent variables, user perceived value as the dependent variable, and user loyalty as the dependent variable to explore the influence of the core competitiveness and brand personality of the short video industry on user loyalty. The research model is shown in Fig. 1.

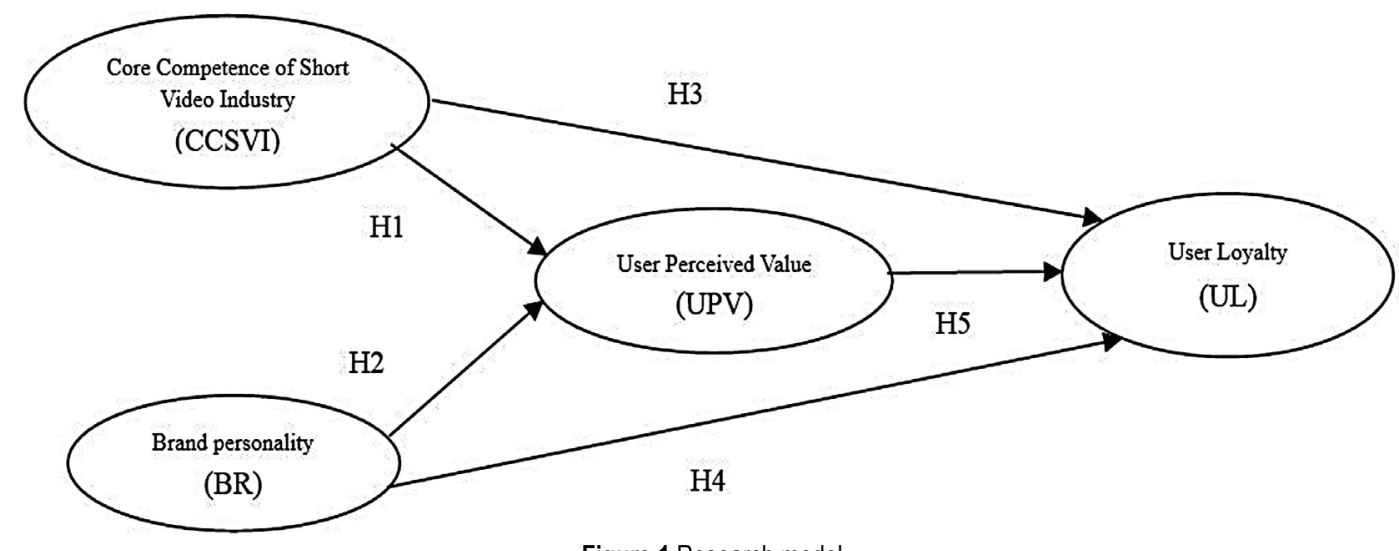

Figure 1 Research model

\subsection{Research Hypotheses}

H1: The core competitiveness of the short video industry has a significant positive impact on user perceived value.
$\mathrm{H} 2$ : Brand personality has a significant positive impact on user perceived value.

H3: The core competitiveness of the short video industry has a significant positive impact on user loyalty.

H4: Brand personality has a significant positive impact on user loyalty. 
H5: User perceived value has a significant positive impact on user loyalty.

\subsection{Research Method}

According to the purpose of the study and the characteristics of the research object, this study adopts the questionnaire survey method, taking short video users in China as the research object. Questionnaire content mainly includes the further dimension quantification of the core competitiveness of short videos, brand personality, user perceived value, and user loyalty. The design of the main questions is based on the operational definition of variables in the following. The survey period was from November 25, 2018 to December 27, 2018. First, 100 questionnaires were distributed in the pre-research stage, and problems were identified through the feedback of 100 customers to further improve the questionnaire content. Second, in the implementation of the formal questionnaire survey, 600 questionnaires were sent out. After the questionnaires were recovered, the data were checked with Excel, and 24 copies were invalid. Ultimately, 576 valid questionnaires were recovered at a rate of $96 \%$. SPSS 22.0 was used for reliability analysis, factor analysis, and equation model analysis of the results of the valid questionnaires.

\subsection{Operational Definition of Variables}

Based on the viewpoints of Coombs [9] and other Chinese scholars, this paper studies the definition and measurement of the core competitiveness of short video websites. First, in the current environment where the Internet has been extremely popular, the form of user receiving information is transiting from the graphic era to the video era. The levels of a large number of video content are uneven. Although some Internet platforms have enough user data information to understand the user's interests, the randomness of the content makes the user's basic reading data deviate from his real reading needs and then reduces the accuracy of data modeling. How to accurately promote the best quality and rich content to users is one of the innovative dimensions of the core technology of the short video industry in the future.

Second, the amount of user traffic is an important indicator to measure the success of short video platforms. These platforms can enhance their popularity by rapidly increasing traffic to attract users' attention, thereby further realizing business value and distinguishing themselves from competitors. The short video sector has a seemingly low threshold in a high threshold industry. The production team should prepare a full strategic plan in lighting, content, later stage, and marketing to produce high-quality short video content. Thus, a high-quality professionally generated content (PGC) platform is the second dimension of user experience in the short video industry.

Third, at present, everyone in the short video industry is a disseminator of information. This condition is different from the past when only organizations, enterprises, or governments had a voice in the media, and users were isolated from one another. The mode of short video information dissemination is a fission mode. The speed and coverage of information dissemination are much higher than those of other media products, and the information transmission can increase exponentially (Fig. 2 shows the information dissemination model of short video). Thus, in this study, the fission information dissemination model is the third dimension of coordination resources of the short video industry. In summary, the core competitiveness of the short video industry can be quantified from three aspects: accurate content distribution, high-quality PGC platform, and fission information dissemination.

The operational definition of brand personality refers to the four dimensions obtained by Aaker [1] through empirical research, namely, innocence, ability, stimulation, and roughness, which are selected for measurement operation.

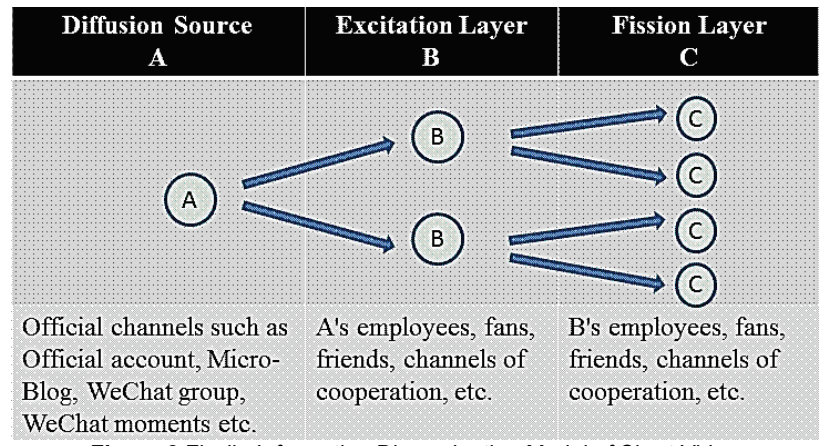

Figure 2 Fissile Information Dissemination Model of Short Video

Table 1 Brand personality dimension

\begin{tabular}{|c|c|}
\hline Brand personality dimension & Brand personality traits \\
\hline Innocence & $\begin{array}{c}\text { Honesty, love the family, } \\
\text { happiness, sincerity }\end{array}$ \\
\hline Stimulation & Energy, courage, fantasy, fashion \\
\hline Ability & $\begin{array}{c}\text { Trustworthiness, responsibility, } \\
\text { reliability, success }\end{array}$ \\
\hline Roughness & $\begin{array}{c}\text { Strength, sturdiness, } \\
\text { adventurousness, solidity }\end{array}$ \\
\hline
\end{tabular}

According to the strategic analysis of enterprise competitiveness based on customer value (Liu, 2018), the operational definition of user perceived value of service enterprises consists of functional value, social value, emotional value, knowledge value and convenience value.

Shankar [24], Rahul and Tridas [23] provided the operational definition in terms of behavioral loyalty (frequency of use and duration of use). Other ideas have been presented by Chaudhuri and Morris [7], Jones and Taylor [14] that about users' attitude loyalty, specifically self-perceived loyalty and ability to switch to competitors' tolerance.

\section{RESULTS}

In this study, SPSS and AMOS statistical software are used to test the reliability and validity of the survey data, then hypothesis test is carried out by constructing structural equation model, and the following test results are obtained.

\subsection{Reliability Test}

Reliability analysis mainly measures the stability and reliability of variables by checking internal consistency. The reliability analysis methods mainly include retest, duplicate, half-fold, and $\alpha$ reliability coefficient method.

This study aims to use the method of $\alpha$ reliability coefficient to determine the reliability of measurement 
content by calculating Cronbach's $\alpha$ coefficient. A coefficient of $0.80-0.90$ indicates very good reliability; a coefficient of $0.70-0.60$ means good reliability; and a coefficient of $0.61-0.65$ shows acceptable reliability. The Cronbach's $\alpha$ coefficient is proportional to the reliability of measurement content, that is, the greater the $\alpha$ coefficient, the greater the reliability of measurement content.

By using SPSS statistical analysis software, we can obtain the values of Cronbach's $\alpha$ coefficient, as shown in Tab. 2. All of the values are above 0.6. Thus, we can judge that each item has internal consistency and good stability, which fully conforms to the scope of reliability measurement in this study.

Table 2 Result of reliability test

\begin{tabular}{|l|c|c|c|}
\hline \multicolumn{1}{|c|}{ Variable types } & Variable & $\begin{array}{c}\text { Number of } \\
\text { entries }\end{array}$ & Cronbach's $\alpha$ \\
\hline Independent variables & CCSVI & 3 & 0.790 \\
\hline Independent variables & BR & 4 & 0.851 \\
\hline Lurking variable & UPV & 5 & 0.776 \\
\hline Dependent variable & UL & 2 & 0.635 \\
\hline
\end{tabular}

\subsection{Validity Test}

The scales used in this study are widely applied in measuring core competitiveness, brand personality, and user loyalty. After empirical testing by foreign scholars, Chinese scholars have tested the universal applicability of these scales, thereby ensuring a profound theoretical and practical basis. Therefore, this study only uses structural validity analysis in testing the structural validity of the questionnaire to confirm whether a certain degree of fit exists between the measured data and the hypothesis.

Factor analysis is used to test the validity. The purpose is to describe the relationship between multiple questions or variables in the questionnaire with a few factors and to reflect most of the data information of the questionnaire with fewer factors. The result of the validity test is obtained by SPSS statistical analysis, as shown in Tab. 3. The weight values of all variables are more than 0.6 , thereby indicating that the scale has good constructive validity.

Table 3 Results of validity test

\begin{tabular}{|c|c|c|c|c|c|c|c|c|c|c|c|c|c|c|}
\hline \multirow{2}{*}{ Composition } & \multicolumn{14}{|c|}{ Project } \\
\hline & BP1 & $\mathrm{BP} 2$ & BP3 & BP4 & UPV1 & UPV2 & UPV3 & UPV4 & UPV5 & CCSVI1 & CCSVI2 & CCSVI3 & UL1 & UL2 \\
\hline 1 & .816 & .750 & .815 & .717 & .279 & .183 & -.113 & -.091 & .074 & .117 & .294 & .240 & .301 & .220 \\
\hline 2 & .080 & .074 & .099 & .072 & .713 & .783 & .627 & .692 & .719 & -.013 & .081 & .016 & .092 & .157 \\
\hline 3 & .199 & .159 & .169 & .271 & .197 & .119 & .049 & -.092 & -.009 & .851 & .750 & .789 & .063 & .237 \\
\hline 4 & -.045 & .194 & .213 & .297 & -.097 & -.042 & .422 & .322 & .082 & .142 & .139 & .025 & .660 & .779 \\
\hline
\end{tabular}

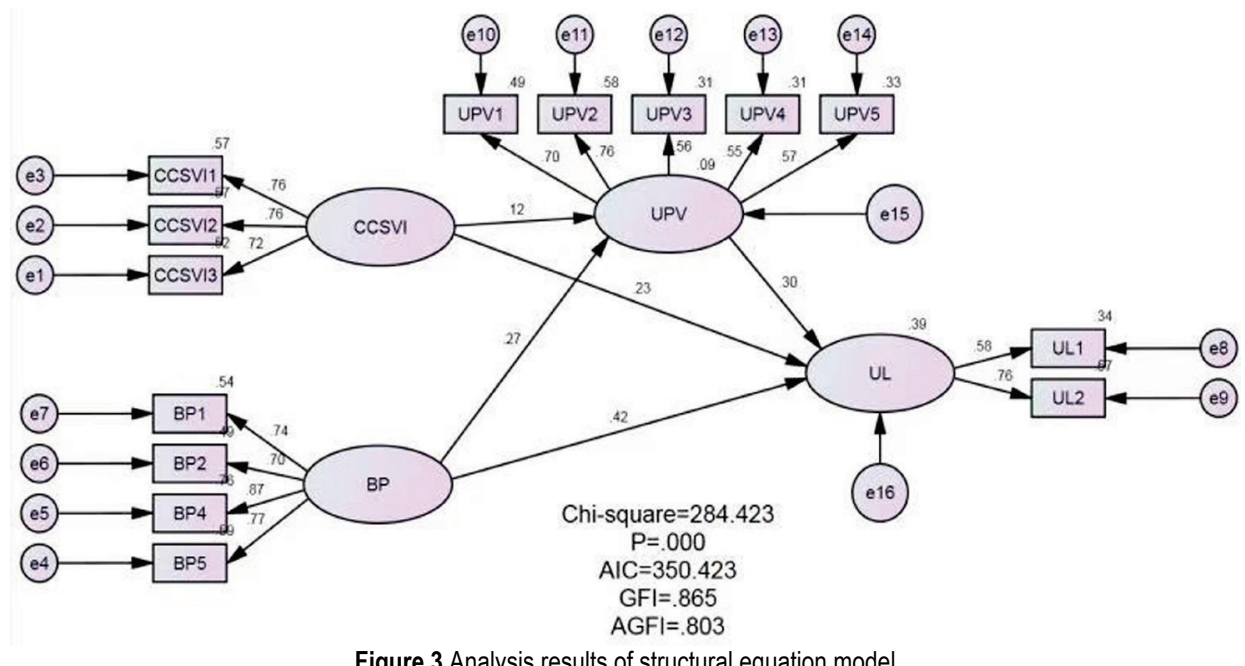

Figure 3 Analysis results of structural equation model

\subsection{Hypothesis Test}

Bogozzi and $\mathrm{Yi}$ [2] proposed the following four ways to verify the basic adaptation index of the model:

(1) No negative error variance should exist in the estimated parameters.

(2) All error variances must reach a significant level (value $>1.96$ ).

(3) The absolute value of the correlation between the estimated parameters statistics cannot be extremely close to 1.

(4) The factor load between the potential variable and its measurement index is preferably greater than 0.6 .

Thus, the basic adaptation index of the model is established in the aforementioned four aspects. Then, the overall pattern adaptation test can be conducted. The fitness of structural equation model is generally determined by chisquare value, AIC, GFI, AGFI and other indicators.
Structural equation model analysis was conducted to obtain the following test results in Fig. 2: chi-square $=284.423$, $A I C=350.423, G F I=0.865$, and $A G F I=0.803$. Considering the criterion of index judgment, we can confirm that this result can pass the model adaptation criteria.

\begin{tabular}{|c|c|c|c|c|c|c|}
\multicolumn{7}{l}{ Table 4 Results of hypothesis test } \\
\hline & & & Estimate & SE & CR & P \\
\hline UPV & $<---$ & CCSVI & 0.122 & 0.076 & 1.601 & 0.109 \\
\hline UPV & $<---$ & BP & 0.245 & 0.07 & 3.496 & $* * *$ \\
\hline UL & $<---$ & CCSVI & 0.173 & 0.064 & 2.717 & 0.007 \\
\hline UL & $<---$ & BP & 0.294 & 0.068 & 4.359 & $* * *$ \\
\hline UL & $<---$ & UPV & 0.227 & 0.07 & 3.229 & 0.001 \\
\hline
\end{tabular}

At the same time, according to the hypothesis test of the structural equation, the path results in Tab. 4 can be obtained, and the following conclusions can be drawn: 
H1: The positive effect of the core competitiveness of the short video industry on user perceived value is not established.

$\mathrm{H} 2$ : Brand personality has a significant positive effect on user perceived value.

H3: The core competitiveness of the short video industry has a significant positive effect on user loyalty.

H4: Brand personality has a significant positive effect on user loyalty.

H5: User perceived value has a significant positive effect on user loyalty.

\section{CONCLUSIONS}

With the advent of "Industry 4.0" after the era of live network broadcasting, the short video industry is expected to undergo further refinement and development. This study applies the research results on core competitiveness, brand personality, user perception, and user loyalty to the short video industry. Taking full account of the differences between the Internet and traditional industries and using 576 valid sample data from coastal areas of China, this study analyzed the reliability, validity, and structural equation by using SPSS statistical software. The results not only solve the research gap on the impact of core competitiveness and brand personality on user loyalty in China's short video industry, but also provide a useful reference in building core competitiveness, establishing brand personality, forming a long market life cycle, and strengthening brand characteristics to maintain user loyalty. Based on the research results, the following conclusions are drawn:

(1) The positive influence of the core competitiveness of the short video industry on the perceived value of users is not established, indicating that the short video industry may appear as a new industry for a short period, the core competition is not mature yet, and the technical means between the industries are similar, without letting users feel differences in perceived value.

(2) Brand personality has a significant positive influence on user perceived value, indicating that most platforms in the short video industry have their own distinctive brand characteristics and competitors, which enable Chinese users to find value in line with their needs in the process of perceptual value.

(3) The core competitiveness of the short video industry has a significant positive influence on user loyalty, indicating that the big data content algorithms in the core competitiveness of short videos include three aspects: Push of comprehensive, music, informational and tool-based content; High-quality content, images, experiences and characters; Fissile information dissemination: information sharing. All of these aspects have a significant positive effect on the loyalty of Chinese users which is expressed in their behavior and attitude.

(4) Brand personality has a significant positive influence on user loyalty, which shows that "innocence" can represent the users who pursue entertainment and uniqueness (representative short video platforms include Tik Tok and Muse); "stimulation" can represent the users who pursue fantasy and fashion (representative short video platforms include B612 Click, Faceu, and VivaVideo); "ability" can represent the users who pursue responsibility and reliability (representative short video platforms include
Xigua and Miaopai); "roughness" can represent strong and sturdy interests (representative short video platforms include Kuaishou, Huoshan, and others). These four dimensions of brand personality have a significant positive impact on Chinese users' loyalty which is expressed in their behavior and attitude.

(5) User perceived value has a significant positive impact on user loyalty, which indicates the five dimensions of user perceived value, including functional value, social value, emotional value, knowledge value and convenience value, have significant positive effect on user loyalty in behavior and attitude.

Therefore, the short video website should further improve its core competitiveness through creation of original videos with the aim to offer personalized and highquality content, and accurate video push according to the consumer information data and the traces of information released on the Internet by using the technology of big data capture and mining. Short video websites should adopt a diversified content production mode, using UGC (User Generated Content), PGC (Professional Generated Content), and OGC (Occupational Generated Content) and other content production modes comprehensively, and laying emphasis on content innovation. In order to improve users' usage and enhance users' stickiness, the platform can organize video activities and topic discussions, let users voluntarily participate in practice and experience, and stimulate users' creative desire through hot topics, at the same time, attracts customers by developing unique functions and advantages and reducing operation difficulty. In terms of interaction between users and platforms, platforms should use optimization algorithms to enable users to quickly acquire content of interest through search or system push and avoid "information cocoon house" phenomenon. When users get aesthetic fatigue, APP should abandon the exploration of depth of interest and start exploring the breadth to recommend other high-quality content to users. In the transmission, besides online transmission, short video products can be promoted through mass media, such as advertisements on TV and public transportation. This strategy can enhance brand communication, shape the brand image, and encourage users to enhance the visibility of products through subtle influence. Through these measures, short video users can gradually feel the difference in perceived value.

In conclusion, the short video industry should maintain and enhance user loyalty by promoting core competitiveness and shaping brand personality. The conclusions provide insights that can help short video companies or platforms to understand user needs and establish user loyalty.

\section{REFERENCES}

[1] Aaker, J. (1997). Dimensions of brand personality. Journal of Marketing Research, 34(3), 347-356. https://doi.org/10.1177/002224379703400304

[2] Bagozzi, R. \& Yi, Y. (1988). On the evaluation of structural equation model. Journal of Academy of Marketing Science, 16(1), 74-94. https://doi.org/10.1007/BF02723327

[3] Banerjee, P. (2003). Resource dependence and core competence: insights from Indian software firms. Technovation, 23(3), 251-263. https://doi.org/10.1016/S0166-4972(01)00120-1 
[4] Basir, M., Modding, B., Kamase, J., \& Hasan, S. (2015). Effect of services and pricing on loyalty and customer satisfaction in marine transportation services. International Journal of Humanities and Social Science invention, 4(6), 16.

[5] Burgess, J. \& Green, J. (2018). YouTube: Online video and participatory culture. John Wiley \& Sons.

[6] Cao, S. X. (2019). The Impact of Network Innovation and Technology Evolution on Mobile Short Vide. China Broadcast, 8, 18-22.

[7] Chaudhuri, A. \& Morris, B. (2001). The chain of effects from brand trust and brand affect to brand performance: the role of brand loyalty, Journal of Marketing, 65, 81-93. https://doi.org/10.1509/jmkg.65.2.81.18255

[8] Chen, S. H. (2019). The Effect of Audience Psychology on Content Production of Traditional TV and Video Websites. News World, 2, 72-74.

[9] Coombs, R. (1996). Core competencies and the strategic management of R\&D. R\&D management, 26(4), 345-355. https://doi.org/10.1111/j.1467-9310.1996.tb00970.x

[10] Davies, G., Rojas-Méndez, J. I., Whelan, S., Mete, M., \& Loo, T. (2018). Brand personality: theory and dimensionality. Journal of Product \& Brand Management, 27(2), 115-127. https://doi.org/10.1108/JPBM-06-2017-1499

[11] Fang, J., Lei, C., Chao, W., \& Prybutok, V. R. (2018). Coviewing experience in video websites: the effect of social presence on e-loyalty. International Journal of Electronic Commerce, 22(3), 446-476. https://doi.org/10.1080/10864415.2018.1462929

[12] Frederick, F. \& Phil, S. (2000). E-loyal: your secret weapon on the web. Harvard Business Review, (7-8), 105-113.

[13] Hu, Y. (2018). Research on customer loyalty of Internet-based enterprises. China Circulation Economy, 7, 8-9.

[14] Jones, T. \& Taylor, S. (2007). The conceptual domain of service loyalty: how many dimensions. Journal of Service Marketing, 21(1), 36-51. https://doi.org/10.1108/08876040710726284

[15] Jukić, D. (2018). Ekvilibrij korporativne marke: analiza identiteta. Oeconomica Jadertina, 8 (2), 0-47. https://doi.org/10.15291/oec.2739

[16] Kim, P., Vaidyanathan, R., Chang, H., \& Stoel, L. (2018). Using brand alliances with artists to expand retail brand personality. Journal of Business Research, 85, 424-433. https://doi.org/10.1016/j.jbusres.2017.10.020

[17] Le, J. Y. (2019). Analysis of Platform Value Domain of Domestic Short Video Websites. Media Forum, 4, 49.

[18] Lemon, K. (2001). What drives customer equity? Marketing Management, 10(1), 20-26.

[19] Li, N. (2019). Research on Content Production Model of Short Video Platform - Take Douyin short video platform as an example. Journal of News Research, 4, 234-235.

[20] Liu, J. (2018). Strategic analysis of enterprise competitiveness based on customer value. China Packaging, 1, 87-89.

[21] Oliver, R. (1999). Whence consumer loyalty? Journal of Marketing, 63, 33-44. https://doi.org/10.2307/1252099

[22] Qiao, Z. \& Cao, X. (2018). Construction of core competence of enterprises under shared economic environment. Business Economy, 9, 30-32+36.

[23] Rahul, T. \& Tridas, M. (2005). Drivers of web portal use. Electronic Commerce Research and Applications, 4(1), 49-65. https://doi.org/10.1016/j.elerap.2004.10.004

[24] Shankar, V., Smith, A. \& Rangaswamy, A. (2003). Customer satisfaction and loyalty in online and offline environments. International Journal of Research in Marketing, 20(2), 153175. https://doi.org/10.1016/S0167-8116(03)00016-8

[25] Sharma, A., Motta, V., \& Martinez, L. (2019). Effectiveness of short videos to enhance HACCP information for consumers Journal of Foodservice Business Research, 1-14. https://doi.org/10.1080/15378020.2019.1663104
[26] Smith, E. (2001). Seven steps to building e-loyalty. Medical Marketing \& Media, 36(3), 94-102.

[27] Sun, Z., Wan, R., Ding, X., Zhu, Y., \& Zhang, G. (2017). An empirical study of customer satisfaction with marine products wholesale market. Indian Journal of Geo Marine Sciences, 46(7), 1470-1476.

[28] Xie, X. (2016). Reconstruction of core competitiveness of enterprises under the background of mobile Internet. Enterprise Management, 4, 43-45.

[29] Xu, Q. (2018).Empirical research: Construction of brand personality dimensions in social media. Enterprise Economy, 9, 96-102.

[30] Xue, Y. Y. (2019). Research on "Filtering Bubbles" in Short Video under Algorithmic Recommendation Mechanism-Take Tik Tok as an example. New Media Research, 14, 21-22.

[31] Zeithaml, V. (1988). Consumer perceptions of price, quality, and value: a means-end model and synthesis of evidence. Journal of Marketing, 52(3), 2-22. https://doi.org/10.1177/002224298805200302

[32] Zhang, D. (2013). Research on the theory of enterprise corecompetence in dynamic evolution. Economic Research Guide, 3, 20-23.

[33] Kelley, D. (1998). The communication of forgiveness. Communication Studies, 49, 255-271. https://doi.org/10.1080/10510979809368535

\section{Contact information}

Wei CUI, PhD, Professor

Business College of Beijing Union University

A3 Yanjingdongli, Chaoyang District, Beijing, China, 100025

wei.cui@buu.edu.cn

Kai LIAO, PHD Candidate

Department of Global Business Kyonggi University

154-42, Gwanggyosan-ro, Yeong-gu, Suwon-si, Gyeonggi-do, Korea, 16227 249368162@qq.com

Ziyang LIU, PhD, Assistant Professor

(Corresponding author)

Department of Global Business Kyonggi University

154-42, Gwanggyosan-ro, Yeong-gu, Suwon-si, Gyeonggi-do, Korea, 16227

morninglzy@hotmail.com 